\title{
NATIONAL-SCALE INSPECTION OF FLOOD DEFENCE INFRASTRUCTURE WITH REMOTELY SENSED DATA
}

\author{
O.J.Tarrant ${ }^{*}$, C.Hollingworth and C.Hambidge \\ Environment Agency, Bristol, England. \\ * Corresponding author
}

\begin{abstract}
Monitoring flood defence condition is a critical part of the effective management of flood defence infrastructure. In this paper, the use of data on flood defences and floodplains gathered from remote sensing is explored to identify indicators of weaknesses, deterioration and damage. Such indicators are often tell-tale signs of processes that can lead to flood defence failure and breaching. Sources of data and the techniques to analyse those data are discussed. A range of examples are presented that highlight both the value and limitations of bringing together multiple sources of data such as LIDAR and historical mapping to supplement visual-based condition assessments. The paper then, describes the results or a national mapping exercise that has brought these datasets together, and made them available to flood defence inspectors working in the field.
\end{abstract}

\section{Introduction}

It is estimated that over $£ 3$ bn of property is at risk of damage from coastal and fluvial flooding every year in England and Wales (Thorne, Evans and Penning-Rowsell, 2007) Many of these properties are afforded some level of protection from flood defences. In fact, approximately $£ 2$ bn of these damages are avoided on average each year by this system of defences. Nevertheless, flooding still occurs. The impacts are wide ranging, affecting people, their property and the environment; disrupting communities and businesses. The knock-on effects can negatively impact the UK economy as a whole. Typically, impacts occur in places either not currently benefiting from defences, or when floods are so large they exceed the defence or a defence fails and breaches.

Flood defences are 'conditioned' to withstand seasonal floods, but can, and do, fail catastrophically during exceptional flood events, turning a natural disaster into an engineering failure. The breaches in the hurricane protection system around New Orleans during Hurricane Katina are perhaps the most poignant and significant example. In the American Society of Civil Engineers review (Perks, 2007) of 'what went wrong and why', the author states that a large portion of the destruction was caused not only by the storm itself, but also by the storm's exposure of engineering and engineering-related policy failures. The levees and floodwalls breached because of a combination of unfortunate choices and decisions, made over many years, at almost all levels of responsibility. This was not simply just a result of poor design decisions but also, an inspection regime which failed to recognise important weaknesses in the defence system and a lack of appreciation of the over-all system risk.
Following the flood events experienced by much of northern England during the winter of $2015 / 16$, the Environment Agency assessed the condition of over 20,000 of its flood defence assets. Only nine assets were identified to have failed structurally, five of these failures had led to a breach and flooding. The flooding from these breaches did not impact any properties that had not already been affected by the overflow of adjacent defence lengths. The breaches did, however cause significant disruption, particularly during the evacuation of people from near-by villages and to the farmland which was flooded (Tarrant et al., 2017)

A subsequent technical analysis of defence performance (Environment Agency, 2016) determined that many of the embankment failures could be attributed to local irregularities/weaknesses such as sudden changes in flood defence geometry, historical channel crossings, and local low spots. The report recommended that flood defence managers should focus on identifying and resolving these local irregularities/weaknesses.

This paper presents findings from on-going work undertaken by the Environment Agency to address this challenge. The main focus of this work has been to explore the potential of LIDAR (Light Detection and Ranging) to help resolve and identify such local irregularities. The paper provides the reader the necessary background on the existing visual flood defence condition assessment process and its strengths and weaknesses. It details the Environment Agency LIDAR capability and archive. Past research that has aimed to improve condition inspection is summarised. A case made for the use remotely sensed data to improve these inspections.

The paper then builds on from the research reported by Tarrant et al. (2017). In this earlier paper, the results from a series of 
investigatory workshops led by the Environment Agency were presented. These workshops brought together flood risk managers and engineers with geospatial analysts. These sessions demonstrated the potential value of integrating local engineering knowledge held within the Environment Agency's operational Flood Risk Management teams with that of the Environment Agency's expert image analysts in the Geomatics Department. The workshop process proved to be extremely productive in developing a lot of high quality, relevant and quantitative information about possible defence performance, deterioration and locations of weaknesses. Furthermore the development process showed the power of integrating multiple sources of remotely sensed data and mapped information in a GIS environment. Whilst the workshop process was clearly useful for investigating relatively limited stretches of defence system, it was too resource intensive to facilitate a nationalscale study.

This paper details the subsequent work to develop methods to generate national data layers consisting of a sub-set of the key defence performance indicators derived from LIDAR data. The paper also describes how the data is serve in a format usable both in the field and office.

\section{Background}

\subsection{Flood defences in England}

The replacement value of the defence infrastructure in England is in the order of $£ 40 \mathrm{bn}$ (Environment Agency, 2017). The Environment Agency has a strategic oversight of this infrastructure which consists of over $8000 \mathrm{~km}$ of flood defences, 212 reservoirs and 22,300 moveable structures such as flood gates and barriers. Over 1 million properties in England benefit from these defences.

Management of defence infrastructure is however, fraught with challenges. Peyras et al. (2017) drawing on their experience of French flood levees, but generalising to all defences internationally, outlined just some of the technical challenges. They illustrate the complexity of defence infrastructure in their discussion of varying scales, contexts, construction materials, age, modes of failure and rates of deterioration. Peyras' experiences of levees in France are analogous to those in the UK. Many defence in the UK are old (sometimes built up over centuries) poorly known structures, composed of heterogeneous construction materials.

\subsection{The strengths and limitations of defence condition inspection}

Given the scale of the defence infrastructure in England and the uncertainty around their construction, the task of routine condition monitoring is a considerable undertaking. This is achieved with a simple, risk-based and pragmatic visual inspection. The Environment Agency's defence condition inspection process can be summarised as follows:

- All main river and coastal defences are visually inspected by the Environment Agency in England at a frequency determined by their probability and consequences of failure;
- flood defences are grouped into flood risk management systems and classified as low, medium, or high risk;

- $\quad$ those assets deemed to be high risk, are inspected to assess their condition every 6 months;

- the inspection process is based on expert judgement guided by a Condition Assessment Manual (CAM) (Environment Agency, 2012) - condition grades are summarised in Table 1; and,

- the inspection is delivered by accredited operational teams.

Table 1: Visual condition assessment grades from CAM (Environment Agency 2012).

\begin{tabular}{|c|c|c|}
\hline Grade & Rating & Description \\
\hline 1 & $\begin{array}{l}\text { Very } \\
\text { Good }\end{array}$ & $\begin{array}{l}\text { Cosmetic defects that will have } \\
\text { no effect on performance }\end{array}$ \\
\hline 2 & Good & $\begin{array}{l}\text { Minor defects that will not } \\
\text { reduce the overall performance } \\
\text { of the asset }\end{array}$ \\
\hline 3 & Fair & $\begin{array}{l}\text { Defects that could reduce } \\
\text { performance of the asset }\end{array}$ \\
\hline 4 & Poor & $\begin{array}{l}\text { Defects that would significantly } \\
\text { reduce the performance of the } \\
\text { asset. Further investigation } \\
\text { needed }\end{array}$ \\
\hline 5 & Very Poor & $\begin{array}{l}\text { Severe defects resulting in } \\
\text { complete performance failure }\end{array}$ \\
\hline
\end{tabular}

Wallis, Long and Smith (2012) call visual inspection an, "essential function" in flood defence asset management, as a key component of the day to day management of any defence system. Visual condition inspection has many strengths. Firstly, it is easy, flexible and practical to be carried out regularly for all types of defences. The inspections in the England cover many types of defence including, flood walls and embankments, but also weirs, gates, culverts, flood barriers, and natural systems such as sand dunes and beaches.

Secondly, training and supporting materials (such as the CAM) are well developed, tested, and delivered to an accredited level. This makes it possible to train many people to undertake inspections quickly. Following the flood events of the winter of 2013-14 the Environment Agency trained 200 military personnel to complete a 'state-of-the-nation' flood defence inspection in 5 weeks. This task would have normally taken the Environment Agency's inspectors two years to complete - see (BBC, 2014). The training is therefore clearly effective and scalable when necessary.

Finally, it is an easy measure of performance, understood by decision-makers at all levels. Flikweert and Simm (2008) outline the role of the visually derived condition grade in setting important performance targets for the Environment 
Agency. At the level of individual assets, the Environment Agency's teams define performance specifications for the maintenance of each defence in terms of the condition grade. This means that each defence has a 'target condition grade' or minimum standard it must be maintained to. This is grade 3 (fair) for most defences with a condition grade 2 (good) for defences protecting large numbers of people and property. It is this target grade that determines how, and to what frequency, the Environment Agency's teams have to maintain the defence, in order to achieve this minimum standard. The target condition grade is also used as an indicator for the performance of the organisation as a whole. One of the Environment Agency's Key Performance Indicators (KPIs) relates to the percentage of defences that meet their target condition grade. This is currently set at $98 \%$ (i.e. $98 \%$ of all defences have to be at, or above, their target condition). The visually derived condition grade are therefore ubiquitous at all levels in the flood risk management in the England.

Issues with visual inspection monitoring are well documented (e.g., Long and Simm, 2006; Tarrant et al., 2017; Wallis, et al., 2012). Long et al. (2006) state that perhaps, the single most significant limitation is that only the surface of the flood defence can be inspected. Important geotechnical processes of deterioration occurring inside the flood defence are left unchecked. If there are surface features indicating a weakness in the defence, these characteristics are often only a partial expression of more advanced sub-surface deterioration processes.

A reoccurring criticism of the visual inspection process in the UK is that, it lacks any real level of quantification of those important parameters that affect performance (e.g., Long et al., 2011; Mériaux and Royet, 2007; Tourment, 2013). These references emphasise a missed opportunity associated with the collection of geometric data relevant to the structural stability of the defence, such as the height or the steepness of its sides. As new survey technologies emerge and become cheaper, the opportunity to collect these data during the inspection process is becoming more realistic.

Equally important, but lacking from the current inspection regime, is also consideration of the wider context of the defence; where the defence sits in the floodplain and how aggressive that environment is. For example, knowledge about the soils a defence is founded on and how those soil types may change along a defence length, is an essential piece of information to help understand likely performance.

There is clearly room to incorporate remotely sensed data in the inspection process to help address some of these short comings.

\subsection{The Environment Agency's LIDAR capability and archive}

Tarrant et al. (2017) discuss different types of remotely sensed data that could improve defence condition inspection and outlines the Environment Agency's capability to capture LIDAR. The Environment Agency operates two LIDAR instruments on separate fixed wing aircraft. The aircraft position and attitude are calculated using differential global positioning system (GPS) and an inertial measurement unit (IMU). The position of reflected laser pulses can be calculated very accurately using the spatial information measured by the GPS and IMU at a rate of hundreds of thousands of measurements per second. This technique results in the production of a cost-effective, highly accurate, and continuous terrain map.

The Environment Agency regularly produces a composite Digital Terrain Model that combines the "best of breed" height data sets currently available. This is called the Environment Agency Integrated Height Model (EAIHM). The Digital Terrain Model is a resampled $2 \mathrm{~m}$ resolution height data set that includes EA LIDAR data, where available, followed by TELUS LIDAR (2016) data and finally filled in using the national coverage AirPhoto Great Britain (APGB) photogrammetry data set where the other data sets are not available.

As of 2017 The Environment Agency start an ambitious programme of LIDAR capture at 1 metre horizontal resolution across $100 \%$ across the whole of England by March 2020. Currently Environment Agency LIDAR has been captured across approximately $75 \%$ of the land mass of England and Wales, including about $95 \%$ of the flood plains, approximately 90\% of the Environment Agency's flood defences are cover by LIDAR at $1 \mathrm{~m}$ resolution - (Figure 1).

Figure 1 Coverage of LIDAR captured by the

Environment Agency as of 26 October 2017.

Background map (C) Crown Copyright and database rights 2017 Ordnance Survey 100024198

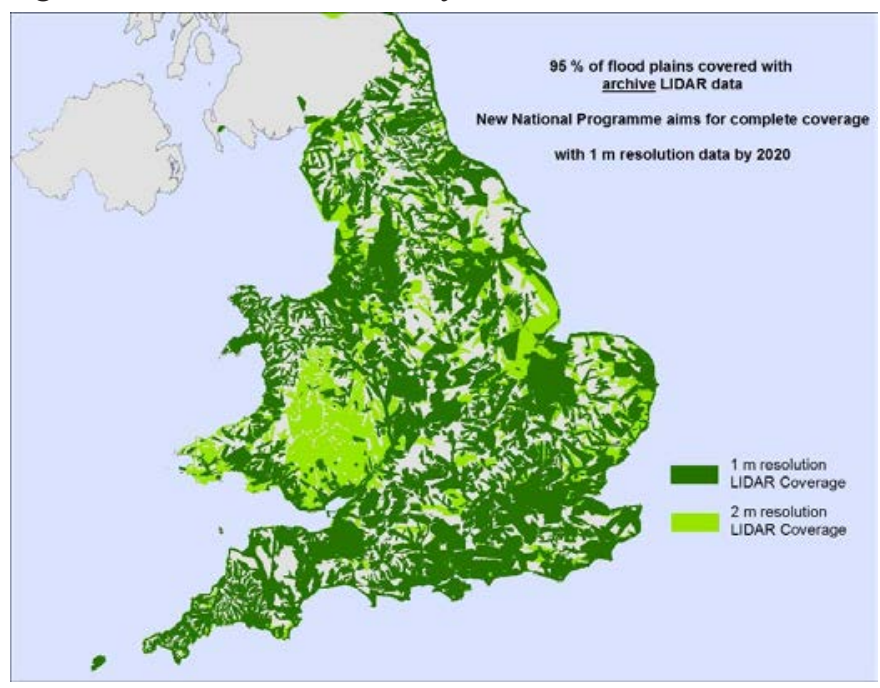

In places a time series of LIDAR data going back to 1998 is available. The Environment Agency's LIDAR data can be accessed, used and shared by anyone under the Open Government Licence, which makes it free of charge and free of restriction, even for commercial use.

Numerous products can be created with LIDAR data, but the main products referred to in this paper are the following: 
- Digital Surface Model (DSM) - This is the height data of the landscape where the surface objects (trees, scrub, buildings, bridges, etc.) are included in the data.

- $\quad$ Digital Terrain Model (DTM) - This is the height data of the landscape where the surface objects (trees, scrub, buildings, bridges etc.) have been removed through a variety of complex filtering algorithms.

- $\quad$ Detrended LIDAR - Detrended LIDAR data sets are modified height data where the macro-topography has been removed (or detrended), leaving the very fine scale features so that they can be viewed without confusion of the varying height of hills and valleys in the landscape. This technique is very powerful for viewing palaeo-channels and other features that have a very fine surface expression.

\section{Strategies to improve visual condition inspection}

The challenge of improving the visual condition inspection process has motivated researchers to explore this issue. The work of Long et al., (2006) sought to relate the superficial appearance of a flood defence to aspects that reflect the structural integrity and reliability. Flikweert and Simm (2008) added to our understanding of performance by relating condition grading to learning from expert reviews of historic and past failures. Other authors have explored the potential of the integration of other types of survey data such as LIDAR with visual inspection (Wallis, et al, 2013; and, Tarrant et al, 2017 ) and hence bring a degree of quantification to the process.

\subsection{Learning from past performance}

Learning from past defence failures by reviewing performance is an activity the Environment Agency has completed routinely after every major flood event since 2007. Flikweert and Simm (2008) report on the work carried out following the 2007 flood event. This review effectively set the template for the four reviews that have taken place since 2007 following flooding and defence failures. These include, 2009 (Cumbria) 2012 (Lincolnshire) 2013/14 (East coast storm surge) and 2014/15 (Cumbria and Lancashire).

These reviews are based on a collation of engineering data gathered from surveys with anecdotal information in order to re-create a 'story' of what might have actually happened in each event. The reviews process develops knowledge from highly situated and localised data sources. Data is generated and analysed to determine loading, strength and failure modes during the event and then compared with existing models of defence performance. This analysis helps to identify the processes and contributing factors leading to failure from which conclusions can be drawn and recommendations developed - see Figure 2.
Figure 2 Learning lessons from a breach defence at the River Torne during the Summer 2007 floods (from Flikweert and Simm, 2008)

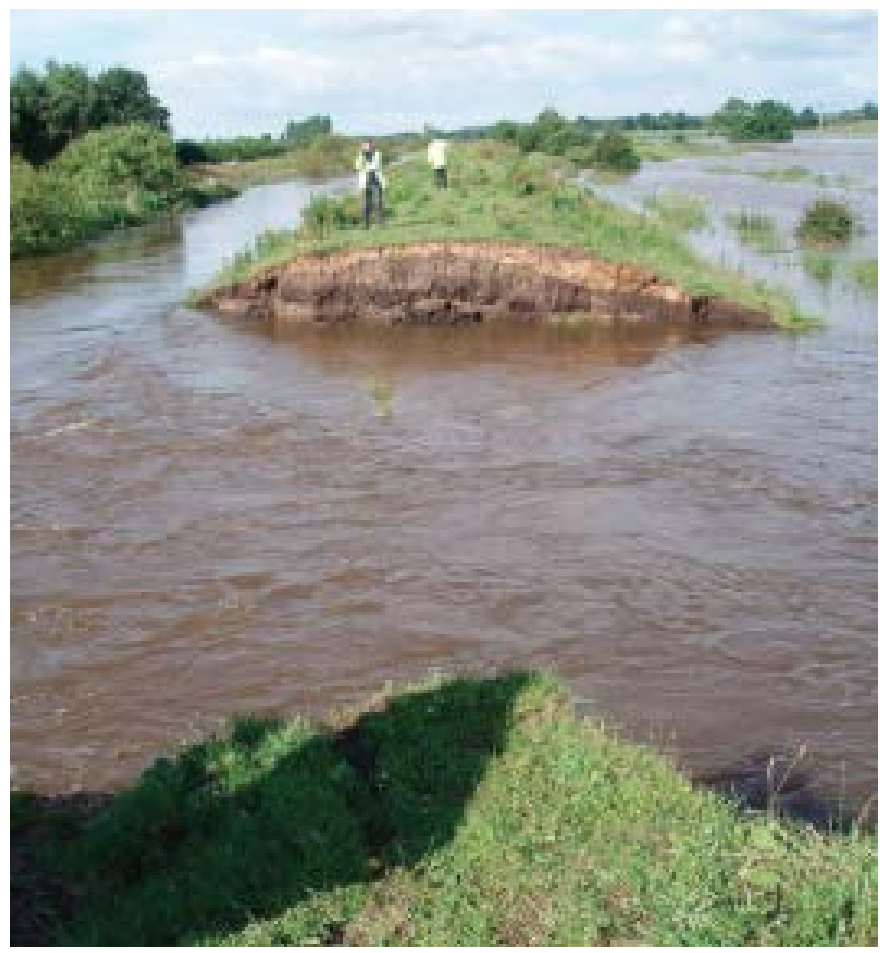

An important finding reported by Flikweert and Simm (2008) was that three of the four breaches occurred when the waterlevel was well below the top of the defence. This meant that the breaches were caused by geotechnical failure modes governed by processes active inside the defences. The authors discuss their suspicion, that failure in these three examples, was initiated by 'local irregularities' in the defences. Stating, that the breaches were not caused by overall poor quality of design or condition. In some of the cases these irregularities may have been visible (such as the presence of rabbit holes) and hence captured in the condition grade. It is more likely however, that they were invisible to the inspectors and were related to the embankment fill material or to the subsoil.

To verify this theory authors looked back to the last visual inspection reports which, would have recorded damage caused by burrowing animals, and found no 'correlation' between condition grade recorded and breach location. Although, it must be noted that with such a small sample, a statement of the probability of correlation can't be made in a true statistical sense. The lack of any correspondence between the poor condition grades and the actual occurrences of breaching, demonstrates that the condition grading procedure wasn't capturing all of the important failure modes in this occasion (i.e. the condition grade wasn't a good indicator of actual defence performance).

This finding led a recommendation that local defence characteristics, such as subsoils and fill materials, should be assessed to check if these warranted a stricter target [condition grade]. It was recognised however, that this recommendation whilst sounding simple was not straightforward to act upon on a national-scale. In fact, they likened it to the search for the 
proverbial 'needle in a haystack', due to the large number of defences and the uncertainty about the type of irregularity that is likely to cause a breach. Although, the authors recognise that this search can be rationalised by focussing on the defences in the highest risk systems, through continued learning gained from analysis of historic failures and with the use on existing and new survey techniques.

\subsection{Using remotely sensed data}

Both Long et al. (2011) and Mériaux (2007) have explored the potential of using remotely sensed data collected about defences from novel platforms such as drones. Their research was however, generally directed toward clarifying the use of new technology for the collection of the important geometric parameters. The work reported Tarrant, et al (2017) differed as it looked to existing sources of remotely sensed data for the identification of key features in, on, or around a flood defence that might affect the performance of that defence. 'Performance features' and how they are likely be captured in different remotely sensed dataset were then linked to possible failure modes. The performance features were categorised as either signs weakness, deterioration or damage which were defined as:

- Weakness - a feature of a defence [or its foundation] that is likely to reduce its performance as compared to a more homogenous counterpart.

- Deterioration - a time-based process initiated by a physical or chemical agent or process, such as waves, tides, temperature variation, animal and human activities, and/or loading and un-loading (adapted from ILH 2013).

- Damage - A state of a defence caused by an event or excess use (over and above 'gradual wear and tear' caused by normal rates of deterioration), for example the loss of toe protection due to a storm event.

For example significant weaknesses can be introduced in defences by buried infrastructure such as pipes crossing the embankment. A partial breach occurred in the defence along the Humber Estuary during an east coast storm surge (5 December 2013). Failure occurred at the point of intersection between an old (now in-filled) drainage channel that ran perpendicular to the flood embankment. The drain wasn't known, and the recent visual inspection had graded the defence as 'good'. See Figure 3.

From Figure 3a concrete head wall which was previously buried within the defence is clearly visible. Figure $3 \mathrm{~b}$ highlights the expression of the drainage channel and historic pond in the micro-topography. A crop mark can be seen depicting the line of the drainage channel in panel (Figure 3c). Historic mapping (Figure 3d) confirms the presence of the drainage channel. This figure serves to highlight the power of integrating several sources of remotely sensed data and mapped information to build up a comprehensive picture of the changing context of the flood defence asset.
Figure 3: Humber Estuary - a) Flood defence failure at Blacktoft; b) Detrended LIDAR data; c) Digital aerial photography (true colour); d) Historic (1969) County Series 1:2500 scale Ordnance Survey (OS) mapping data (Red detail)

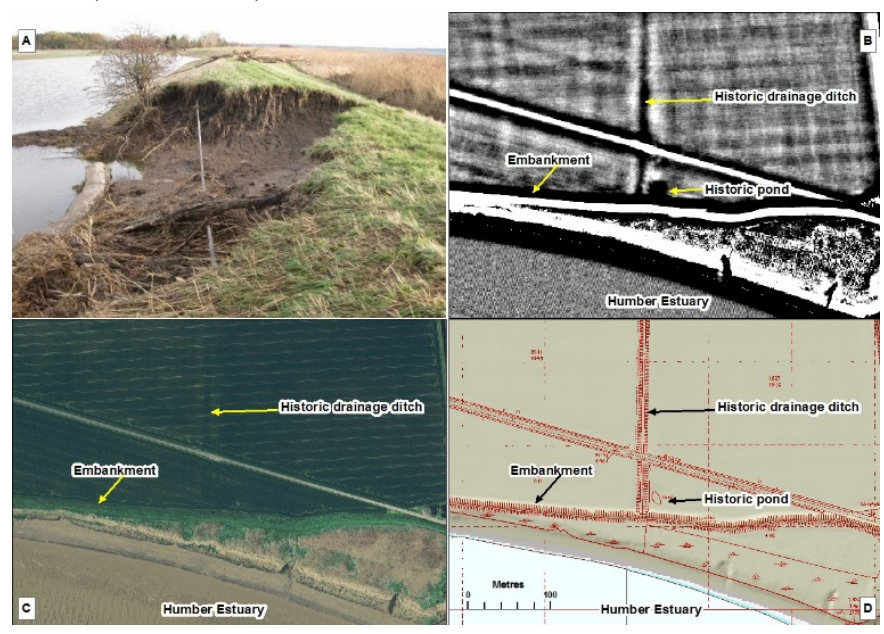

Analysis of these sources of remotely sensed data and the historic mapping would have alerted flood risk managers to this weakness and work to address it programmed.

Data products such as those shown if figure 4 could readily be used to compliment visual condition information in order to help guide more detailed engineering inspection/investigation and also target action during flood events where exceedance/abnormal operation is anticipated.

The case to invest in further work to develop such data products was compelling. The Environment Agency understood that through the use of remote sensing techniques, large geographic areas, that sometimes would be inaccessible to people on the ground, could be covered quickly, repeat surveys could be used to provide information on rates of change; and, expensive ground-based surveys could be targeted a lot more efficiently. These qualities of remote sensing, combined with the facts that high resolution data is increasingly becoming cheaper and easier to store and distribute, justified why such work was timely and likely to offer value for money.

\section{Developing national-scale performance feature data layers}

Following on from the successful initial workshop-based investigations, the Environment Agency has been working to develop specific data layers showing a range of features that might not be readily identifiable during a visual inspection.

This work has focussed on three performance features categorised as weaknesses: firstly, relative low spots along the crest of the defence were analysed. Flood water would start to overflow/overtopping at these locations first, during an extreme flood event. This could cause external erosion of the defence and possibly, breaching. Secondly, defence embankments with excessively steep rear faces (typically 
$>35^{\circ}$ ) were identified. In these situations, if overflow/overtopping of the defence was to occur, surface erosion and scour at the toe of the defence would be likely as water is accelerated down the face of the embankment. Lastly, the points of intersection between palaeo-channels and other features that run underneath a defence embankment were mapped. At these points differential settlement of the defence is possible and the change in soil type could also provide a mechanism and pathway to promote internal erosion which could lead to breaching.

These data layers needed to be produced for the all of the defences in England. The scale of this challenge demanded that the production was automated where possible yet quality strictly controlled. The remaining sections of this paper detail this process.

\subsection{Relative defence crest heights and low spots}

The rationale behind the production of a data layer showing the relative crest heights was not to provide a measure of the absolute height of the defence, rather to help the identification of a local anomaly in crest height - a low spot. In essence this data layer is a visual analysis of the trends in height along the length of the defence showing deviations which typically would not be readily resolvable by the naked eye. And thus, missed during a visual inspection.

Maximum height values were extracted from the LIDAR elevation data at transects stationed every 2 meters perpendicular to the defence centre line. Each defence line is split into segments of no more than 400 metres and/or at river confluences. The average maximum transect height is calculated along each of these sections. Relative crest heights for each transect were calculated by subtracting each individual maxima from the average. This process accounts for the downstream trends in elevation change of the defence crests and enables the analysis to be run over very large areas with a uniform colour palette. Thus, standardising the visual display of the data - See Figure 4.

Figure 4 Show example of relative height analysis to identify low spots

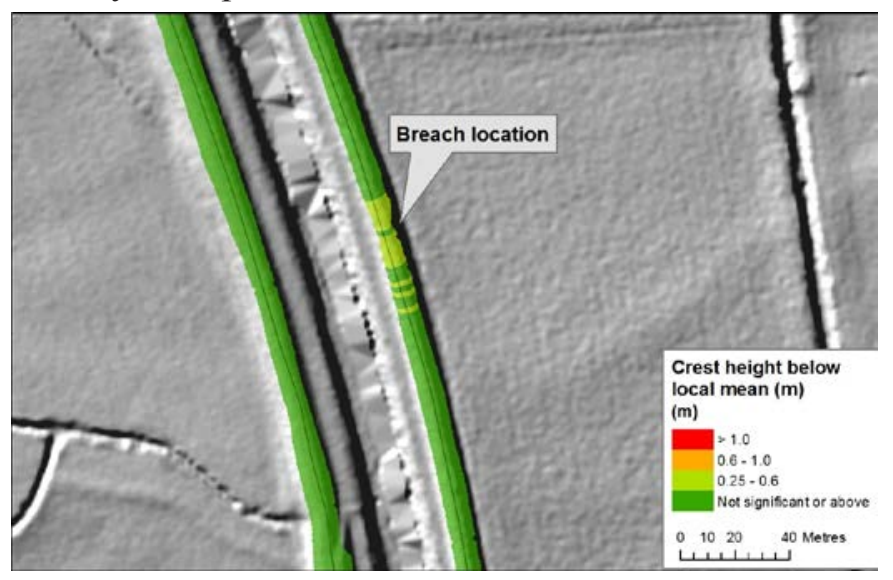

The resolution of the LIDAR data is a controlling factor in the quality of this product. Whilst the $1 \mathrm{~m}$ horizontal resolution data was shown to be effective at resolving the crest heights in most instances, it was recommended to only $2 \mathrm{~m}$ resolution data if you really had no other option, and with great caution.

\subsection{Rear facing slopes}

LIDAR data can be used to rapidly extract cross-sectional information from defences to help inform reliability analysis. However, the suitability of these data for measuring slope angles is again, directly a function of the horizontal resolution and therefore caution has to be exercised not to use data at a resolution not appropriate to the length of the slope being measured. See Figure 5.

Figure 5 Analysis of the rear face slope conducted with the $1 \mathrm{~m}$ resolution LIDAR highlights in red areas where the embankment slope is greater than $35^{\circ}$.

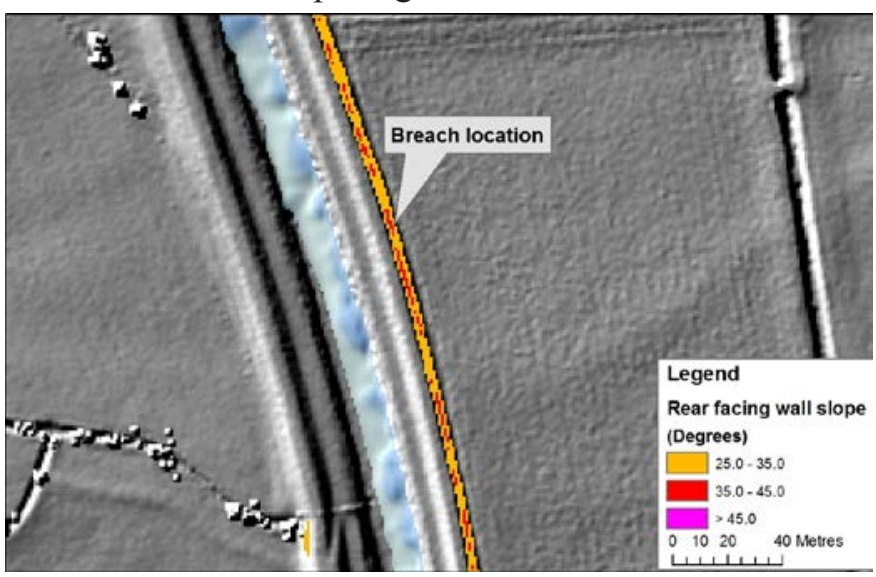

\subsection{Intersection of crossing under defences}

LIDAR is very powerful for viewing features that have a very fine surface expression. Tarrant et al (2017) showed how the detrended LIDAR provided and excellent data source to better understand the palaeo-landscape that current defences are founded on. Often clear evidence of extensive braided channel networks can be seen in the data that are associated with the now constrained watercourses and/or as a result of a previous sea levels. See Figure 6. This makes it very useful for identifying anomalies indicative of changes in the soils and superficial geology. 
Figure 6 a) Aerial photo showing the area where a palaeo-channel crosses a river channels; b) LIDAR data with relative flood defence crest heights analysed
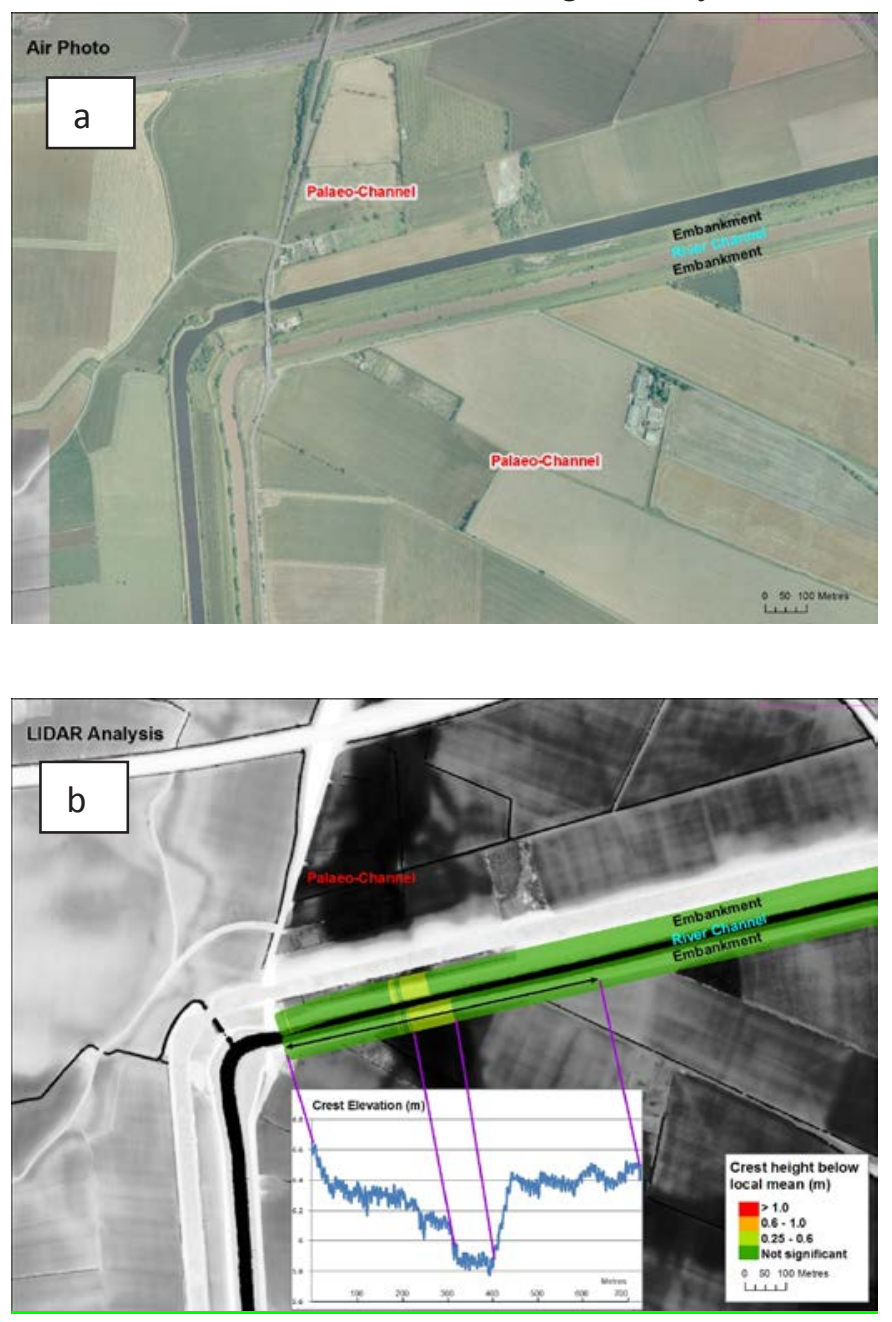

It can be seen from Figure 6a, the palaeo-channel is not visible in the air photo data, nor is it visible on the ground. However the palaeo-channel is clearly visible in the detrended LIDAR data shown in Figure 6b. Similarly, the effect of consolidation of the weaker soils that infill the palaeo-channel can been seen on the height of the embankment crest level.

\section{Delivering the data to operational teams}

An important requirement for the project was to ensure that non-GIS users were able to access and view the full range of data layers that were produced. Equally, the project team were aware that many of the Environment Agency's asset inspectors/engineers do not have the hardware available to store and handle the volumes of data that typify large geospatial datasets. Fortunately now, the challenge of handling and distributing of volumes of data can be solved by cloudbased storage and distribution systems. The Environment Agency had previously developed capability in this area to support its incident response activity, enabling data sharing and visualisations of geospatial data to all levels of user. The major advantage of cloud storage is that the data can be delivered in the form of an interactive web map application. Therefore an intuitive web mapping application that can be viewed across multiple types of device was developed using Arc-GIS online. Figure 7 shows a screen shot from the web-mapping application call SEAL (Surveillance of Embankment Assets with LIDAR).

The data behind SEAL can be viewed and interacted with in a standard web browser on a PC, laptop, GPS-enabled tablet or smart-phone, either on a desktop or out in the field. The technology is maturing to an extent where it is reliable and already being used in field operations throughout the Agency. Data delivered in this format can be visualised in simplified versions as far as possible, for example with the relative crest height data is uploaded as point locations of potential low spots identified within the cross-sections, rather than all of the cross sections themselves. This not only minimises web download times, but also make the web maps less cluttered.

Figure 7: Screenshot from EA's SEAL Web-mapping application

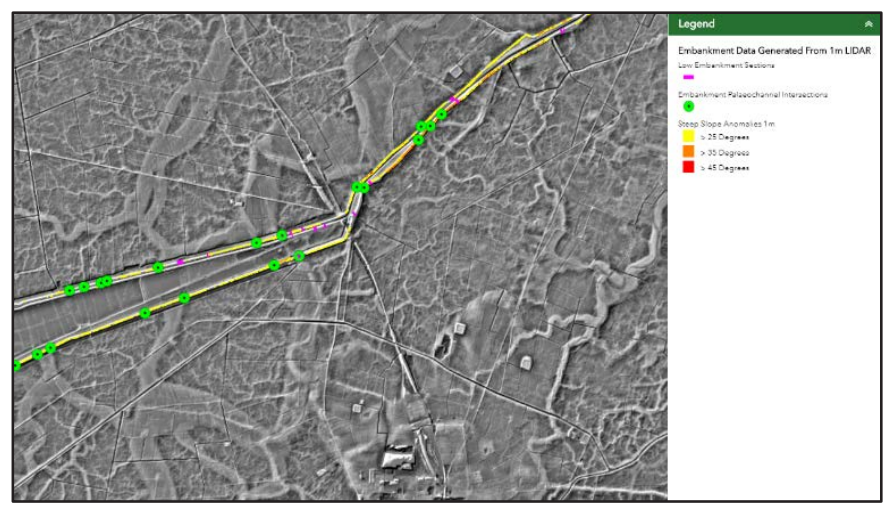

Raster images of the full resolution LIDAR data are available underneath the vector anomaly data layers so that the wider context of in the landscape/data can be seen clearly.

Other useful data layers are provided too. Figure 8 shows how historic ordnance survey mapping can also be projected to help inspectors and engineers interpret potential anomalies and changes overtime.

Figure 8: Screenshot from SEAL web-mapping system shown possible defence anomalies overlaid on LIDAR and historic map. Historic mapping OS six inch, $1888-$ 1913 courtesy of National Library of Scotland"

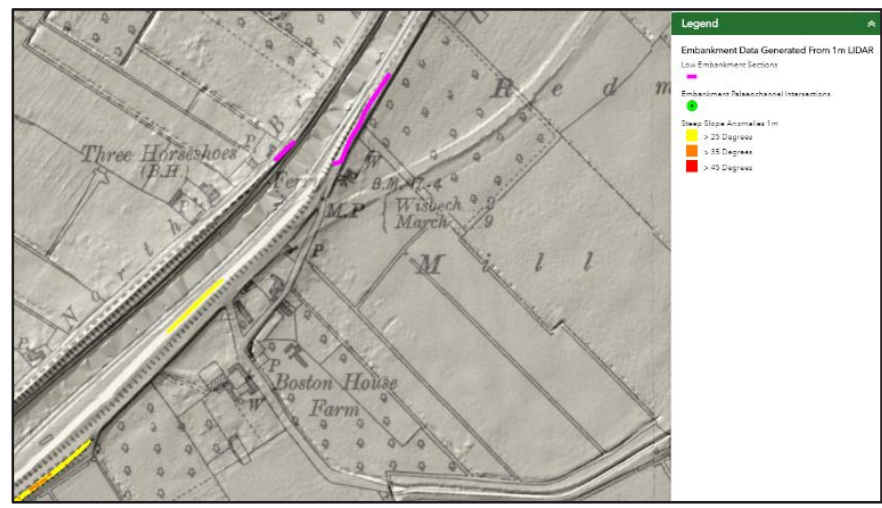




\section{Conclusion}

The process of visual-based condition assessment of flood defence infrastructure is a foundation for effective management. The inspection process has many strengths, particularly ease of provision and interpretation. There are however, weaknesses too. The resulting condition information from a sequence of inspections only captures those deterioration processes that are visible on the surface of the flood defence. It does not provide flood risk managers, with information about inherent weaknesses and deterioration processes that occur within the flood defence. Similarly, the narrow focus of the visual inspection on the defence asset, means that important evidence about how the wider context of the environment and how might be effecting its performance is not accounted for

Remotely sensed data, and particular those data obtained from LIDAR systems, can provide valuable additional information to help better target visual and intrusive condition inspections. Furthermore, these data can provide useful information to help flood risk managers predict likely defence performance during flood conditions.

As survey techniques and platforms continue to evolve at pace, and advances in mapping software and cloud-based data storage develop at a similar rate, large geospatial datasets are now readily accessible by teams working in the field. It is therefore, becoming increasing realistic to use multiple complimentary sources remotely sensed data in the operational environment. The Environment Agency has responded to this opportunity and developed a web-based mapping system that is providing a richer insight in to infrastructure asset performance.

\section{Acknowledgements}

The work reported was funded by the Joint Environment Agency, Defra, Welsh Government and Natural Resources Wales FCERM Management R\&D Programme.

\section{References}

Anon (2014) UK floods: Army to carry out 'rapid inspection' of defences - $B B C$ News. Available from: https://www.bbc.co.uk/news/uk-26214462 [Accessed 24 January 2019].

Environment Agency (2012) Managing Flood Risk - Condition Inspection Manual. 2 (July), pp. 150.

Flikweert, J. and Simm, J. (2008) Improving performance targets for flood defence assets: Improving performance targets for flood defence assets. Journal of Flood Risk Management [online]. 1 (4), pp. 201-212.

Long, G. and Simm, J. (2006) Improved approaches to condition assessment-volume 2: detailed technical report [online]. Available from: www.floodrisk.org.uk [Accessed 16 July 2018].

Long, G., Smith, M. and Taha, A. (2011) Performance based inspection of flood defence infrastructure: Integrating visual inspection and quantitative survey measurements [online].
Available from: www.floodrisk.org.uk [Accessed 16 July 2018].

Mériaux, P. and Royet, P. (2007) Surveillance, Maintenance and Diagnosis of Flood Protection Dikes: A Practical Handbook for Owners and Operators [online]. Versailles: Quæ.

Perks, A.R. (2007) 'The New Orleans Hurricane Protection System: What Went Wrong and Why.' Canadian Consulting Engineer [online] 48 (6) p.pp. 10. Available from: http://uwe.summon.serialssolutions.com/2.0.0/link/0/eLvHC XMwtV3PS8MwFA5uJ3fyJzoV4kAvUlnTNE0EL47pDoKC GwMvI0tTFGcHYx78732vTX9MUfTgJZS0pIHv8eXlvZcvh ATsvOt94oRA6EQmQkSxMsxyJWOlpwKWe20SWIOC_C K62wHvPYaD6mbIqu9fgYcgB4P0v4B HJQ6IBnMAFowQig ZUZnDA2dGWMd4uZ1V gYk0X.

Peyras, L., Tourment, R., Vuillet, M., Beullac, B., Delaunay, C. and Bambara, G. (2017) Development of an expert-led GISbased approach for assessing the performance of river levees: the Digsure method and tool. Journal of Flood Risk Management [online]. 10 (3), pp. 393-407. Available from: http://dx.doi.org/10.1111/jfr3.12178doi:10.1111/jfr3.12178.

Tarrant, O., Hambidge, C., Hollingsworth, C., Normandale, D. and Burdett, S. (2017) Identifying the signs of weakness, deterioration, and damage to flood defence infrastructure from remotely sensed data and mapped information. Journal of Flood Risk Management [online]. pp. n/a-n/a. Available from: http://dx.doi.org/10.1111/jfr3.12326doi:10.1111/jfr 3.12326 .

Thorne, C.R., Evans, E. and Penning-Rowsell, E.C. (2007) Future flooding and coastal erosion risks [online]. London: Thomas Telford.

Tourment(Irstea), R. (2013) Levee inspection, assessment and risk attribution. In: (no place) CIRIA.

Wallis, M.J., Long, G. and Smith, M.I. (2012) Visual inspections and surveys, remote sensing techniques and sensors for detailed analyses. In: Flood Risk [online]. (no place) ICE Publishing. pp. 43-72. Available from: http://www.icevirtuallibrary.com/doi/10.1680/fr.41561.043do i:10.1680/fr.41561.043 [Accessed 24 January 2019]. 